From the First Department of Medicine, Wilhelminenspital, Vienna, Austria; Cancer Research and Biostatistics, Seattle, WA; Division of Hematology, Mayo Clinic, Rochester, MN; Myeloma Institute for Research and Therapy, University of Arkansas for Medical Sciences, Little Rock, AR; Mayo Clinic, Scottsdale, AZ; Southwest Oncology Group, International Myeloma Foundation and Cedars Sinai Comprehensive Cancer Center, Los Angeles, CA; Hematology Department, Institute of Hematology and Oncology, Hospital Clinic Institut d'Investigacions Biomediques August Pi i Sunyer, BarceIona; Servicio de Hematologia, Hospital Universitario de Salamanca, Centro de Investigacíón del Cancer, Instituto de Biologia Molecular y Celular del Cancer (USAL-CSIC), Salamanca, Spain; Department of Medicine, Nagoya City Midori General Hospital, Nagoya, Japan;

Department of Hematology, University Hospital, Malmö; Department of Hematology, Sahlgrenska University Hospita University of Gothenburg, Gothenburg Sweden; Department of Hematology, Erasmus MC, Rotterdam, the Netherlands; Institute of Hematology and Medical Oncology 'Seragnoli,' University of Bologna, Bologna; Servicio de Hematología, Hospital dell'Università di Torino, Ospedaliero-Universitaria San Giovanni Battista di Torino, Torino, Italy Division of Hematology, Centre Hospitalier Universitaire Hotel-Dieu, Nantes; and Service d'Hématologie, Hôpital

Purpan, Toulouse, France.

Submitted July 28, 2009; accepted November 18, 2009; published online ahead of print at www.jco.org on February 22, 2010

Authors' disclosures of potential conflicts of interest and author contributions are found at the end of this article.

Corresponding author: Heinz Ludwig, MD, Department of Medicine I, Center of Oncology and Hematology, Wilhelminenspital, Montleartstr 37, Vienna, Austria 1160; e-mail: heinz.ludwig@wienkav.at. (c) 2010 by American Society of Clinical Oncology

0732-183X/10/2809-1599/\$20.00

DOI: $10.1200 / J C O .2009 .25 .2114$

\title{
Survival and Years of Life Lost in Different Age Cohorts of Patients With Multiple Myeloma
}

Heinz Ludwig, Vanessa Bolejack, John Crowley, Joan Bladé, Jesus San Miguel, Robert A. Kyle, S. Vincent Rajkumar, Kazuyuki Shimizu, Ingemar Turesson, Jan Westin, Pieter Sonneveld, Michele Cavo, Mario Boccadoro, Antonio Palumbo, Patrizia Tosi, Jean-Luc Harousseau, Michel Attal, Bart Barlogie, A. Keith Stewart, and Brian Durie

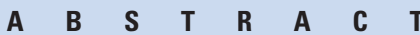

\section{Purpose}

To assess the impact of age on outcome and to analyze the projected years of life lost in patients with multiple myeloma.

\section{Patients and Methods}

Ten thousand five hundred forty-nine patients were evaluated; 6,996 patients were treated with conventional chemotherapy, and 3,553 patients were treated with high-dose therapy with autologous stem-cell transplantation.

\section{Results}

Mean observed and relative overall survival times in the entire cohort were 3.7 and 3.9 years, respectively. Observed survival decreased steadily from 6.4 years in patients younger than age 50 years to 2.5 years in patients $\geq$ age 80 years. A similar decrease was noted for relative survival. Higher age correlated significantly with higher International Staging System (ISS) stage. Relative excess risk of death differed significantly between 10-year age cohorts beginning from age 40 years $(P<.001$ for age 50 to $59 v$ age 40 to $49, P<.001$ for age 60 to $69 v$ age 50 to $59, P<.001$ for age 70 to $79 v$ age 60 to 69 , and $P=.009$ for age $\geq 80 v$ 70 to 79). The average years of life lost per patient was 16.8 years in the entire patient cohort and decreased steadily from 36.1 years in patients younger than 40 years old to 4.6 years in patients $\geq$ age 80 years

\section{Conclusion}

Age is associated with higher ISS stage and is an important risk factor for early mortality. Survival declined continuously by each decade from age 50 to age $\geq 80$ from more than 6 to less than 3 years. The average of years of life lost in patients with myeloma is higher than in many other cancers and amounts to more than 30 years in patients younger than 40 years old but decreases to less than 5 years in patients age 80 years or older.

\section{J Clin Oncol 28:1599-1605. (c) 2010 by American Society of Clinical Oncology}

\section{INTRODUCTION}

Multiple myeloma (MM) accounts for $1.4 \%$ of all cancers and for $1.9 \%$ of all cancer mortality, ${ }^{1}$ and the number of new cases per year is 19,920 in the United States ${ }^{1}$ and 28,700 in the European Union. ${ }^{2} \mathrm{MM}$ is a disease of the elderly population, with a median age at manifestation of approximately 70 years in the United States ${ }^{3}$ and 72 years in Europe. ${ }^{4}$ Median survival times are 5 to 7 years in patients treated with high-dose chemotherapy and autologous transplantation and 3 to 4 years in patients treated with conventional chemotherapy. ${ }^{5}$ The majority of patients treated with high-dose therapy and autologous transplantation are younger than 65 years old, whereas patients treated with conventional therapy are usually older than age 65 .

Although survival tends to be longer in younger patients, ${ }^{5-7}$ accurate data on the outcome in patients of different age categories have not been reported. A further important issue regarding information on the projected years of life lost in patients of different age cohorts at diagnosis has not been systematically addressed so far. Estimation of years of life lost provides a more accurate depiction of premature death by weighing deaths occurring at younger ages more heavily than those occurring in older patients and thus functions as an additional tool for quantifying the burden of MM. Here, we report results obtained in a large group of patients with MM treated either with conventional or high-dose therapy. 


\section{PATIENTS AND METHODS}

Data from 10,549 patients were submitted from 17 institutions or study groups in North America, Europe, and Japan. Patients were enrolled between 1982 and 2002. Six thousand nine hundred ninety-six patients received conventional chemotherapy as first-line treatment, and 3,553 patients were subjected to high-dose therapy with planned autologous stem cell transplantation. The median age of patients enrolled onto clinical trials was 60 years, and the median age of other patients was 63 years. Median follow-up time was 3.25 years (maximum, 19.21 years). Patient characteristics are listed in Table 1.

The relationship between prognostic factors and age was assessed using Spearman rank correlation coefficient. ${ }^{8}$ A maximum likelihood model was used to estimate relative excess risk (RER) for death in patients in different age cohorts using a generalized linear model approach with Poisson error structure using exact survival times and collapsed data, as described by Dickman et al. ${ }^{9}$ Estimates of relative overall survival within age groups were determined using the Kaplan-Meier method ${ }^{10}$ and were compared using the log-rank test, ${ }^{11}$ while taking the normal mortality expectations of respective popula-

\begin{tabular}{|c|c|c|}
\hline Characteristic & $\begin{array}{l}\text { No. of Patients } \\
(\mathrm{N}=10,549)\end{array}$ & $\% *$ \\
\hline \multicolumn{3}{|c|}{ Age at start of therapy, years } \\
\hline Median & \multicolumn{2}{|l|}{60} \\
\hline Range & \multicolumn{2}{|c|}{$20-93$} \\
\hline$<40$ & 312 & 3.0 \\
\hline $40-49$ & 1,377 & 13.0 \\
\hline $50-59$ & 3,221 & 30.5 \\
\hline $60-69$ & 3,603 & 34.2 \\
\hline $70-79$ & 1,744 & 16.5 \\
\hline$\geq 80$ & 292 & 2.8 \\
\hline \multicolumn{3}{|l|}{ Sex } \\
\hline Male & 5,253 & 49.8 \\
\hline Female & 5,296 & 50.2 \\
\hline \multicolumn{3}{|l|}{ M component } \\
\hline $\lg G$ & 5,777 & 60.0 \\
\hline $\lg A$ & 2,327 & 24.2 \\
\hline Light chain only & 1,021 & 10.6 \\
\hline $\lg D$ & 294 & 3.0 \\
\hline Biclonal & 8 & 0.1 \\
\hline Other & 202 & 2.1 \\
\hline Missing & 920 & - \\
\hline \multicolumn{3}{|l|}{ ISS stage } \\
\hline I & 2,282 & 28.4 \\
\hline ॥ & 3,113 & 38.7 \\
\hline III & 2,648 & 32.9 \\
\hline Missing & 2,506 & - \\
\hline \multicolumn{3}{|l|}{ Geographic region } \\
\hline Asiat & 983 & 9.3 \\
\hline North America & 3,499 & 33.2 \\
\hline Europe & 6,067 & 57.5 \\
\hline \multicolumn{3}{|c|}{ Patients in clinical trials by region } \\
\hline Asiat & 983 & 100 \\
\hline Europe & 4,864 & 80.2 \\
\hline North America & 2,549 & 72.9 \\
\hline \multicolumn{3}{|l|}{ Age $\geq 50$ years by region } \\
\hline Asiat & 920 & 93.6 \\
\hline North America & 3,009 & 86.0 \\
\hline Europe & 4,931 & 81.3 \\
\hline $\begin{array}{l}\text { Abbreviations: Ig, immur } \\
\text { *Percentages are calcula } \\
\text { tIncludes Japan only. }\end{array}$ & $\begin{array}{l}\text { rnational Staging } \subseteq \\
\text { ng values. }\end{array}$ & \\
\hline
\end{tabular}

tions adjusted for age, sex, year of diagnosis, and nationality into account. Life-tables of estimated population mortality rates for the country of each treating institution were obtained from the Human Mortality Database. ${ }^{12}$ Years of life lost were computed by subtracting the actual survival time of individual patients since diagnosis from the patient's life expectancy at the time of diagnosis based on life-tables from the country of origin. The value of the economic loss as a result of premature deaths was estimated using the willingness-to-pay approach multiplying the years of life lost by a previously published value of a year of life of $\$ 150,000 .{ }^{13}$

\section{RESULTS}

Patient characteristics are listed in Table 1. More than half of the patients $(57.5 \%)$ had been enrolled by European study groups or institutions, and 33.2\% came from North American and 9.3\% from Asian institutions and trials. The majority of patients $(70.3 \%)$ had been enrolled onto clinical trials, and $84 \%$ were 50 years of age or older. $\chi^{2}$ tests for differences by regions in clinical trials or age were significant at $P<.001$. The distribution of prognostic factors by age category revealed a significant correlation between higher age and more advanced International Staging System (ISS) stage $(r=0.13$; 95\% CI, 0.11 to 0.16 ) and between age and the parameters that account for ISS stage, namely $\beta_{2}$-microglobulin ( $r=0.16$; 95\% CI, 0.14 to 0.19 ) and albumin ( $r=-0.11 ; 95 \% \mathrm{CI},-0.13$ to -0.09 ; Table 2$)$. Lactate dehydrogenase and bone marrow plasma cell infiltration as factors reflecting the biology of myeloma were evenly distributed between all age categories $(r=-0.03 ; 95 \% \mathrm{CI},-0.06$ to 0.00 ; and $r=0.00 ; 95 \% \mathrm{CI},-0.02$ to 0.02 , respectively). Median observed and relative survival times in the entire cohort were 3.7 and 3.9 years, respectively, and did not differ significantly between men and women. The median relative survival time decreased steadily in the different age categories from 5.2 years in patients younger than 50 years old to 4.6 years in patients age 50 to 59 years, 3.6 years in patients age 60 to 69 years, 3.1 years in patients age 70 to 79 years, and 2.6 years in patients age $\geq 80$ years (Fig 1A); the corresponding median observed survival times were $6.4,5.3,4.3,3.4$, and 2.5 years, respectively (Fig $1 \mathrm{~B}$ ). In patients age 40 to 49,50 to 59 , and 60 to 69 years, median observed survival times were 5.7, 4.7, and 4.0 years, respectively, in patients treated with conventional chemotherapy and 8.0, 6.7, and 6.2 years, respectively, in patients treated with high-dose chemotherapy and autologous stem-cell transplantation (Figs 1C and 1D).

RER of death was similar between patients age less than 40 years and patients age 40 to $49(\mathrm{RER}=1.034, P=.692)$ but differed significantly between all of the other 10-year age categories, with the younger cohort always showing reduced risk of death (age 50 to $59 \mathrm{v}$ age 40 to 49 : $\mathrm{RER}=1.201, P<.001$; age 60 to $69 v$ age 50 to 59: RER $=1.288, P<.001$; age 60 to $69 v$ age 70 to $79:$ RER $=1.190$, $P<.001$; age $\geq 80 v$ age 70 to 79 : RER $=1.278, P=.009$; Table 3 ). Similar findings were obtained when RER was analyzed by age category separately in men, women, and patients treated with standard therapy. In patients with autologous transplantation, RER was significantly increased in the age category of 60 to 69 years versus 50 to 59 years $(\mathrm{RER}=1.263, P=.0058)$ but not significantly higher in the age category of 70 to 79 years versus 60 to 69 years $(\mathrm{RER}=1.130$, $P=.7463$ ). Increased RER estimates for each age group compared with the adjacent age group indicate a trend toward progressively higher risk of death with increasing age, even after adjustment for expected mortality. 


\begin{tabular}{|c|c|c|c|c|c|c|c|c|c|c|c|c|c|c|}
\hline \multirow[b]{3}{*}{ Factor } & \multicolumn{12}{|c|}{ Age Group } & \multirow[b]{3}{*}{$\begin{array}{l}\text { Spearman's } \\
\text { Correlation } \\
\text { Coefficient }\end{array}$} & \multirow[b]{3}{*}{$95 \% \mathrm{Cl}$} \\
\hline & \multicolumn{2}{|l|}{$<40$ Years } & \multicolumn{2}{|l|}{ 40-49 Years } & \multicolumn{2}{|l|}{ 50-59 Years } & \multicolumn{2}{|l|}{ 60-69 Years } & \multicolumn{2}{|c|}{ 70-79 Years } & \multicolumn{2}{|l|}{$\geq 80$ Years } & & \\
\hline & $\begin{array}{c}\text { No. of } \\
\text { Patients/Total } \\
\text { No. }\end{array}$ & $\%$ & $\begin{array}{c}\text { No. of } \\
\text { Patients/Total } \\
\text { No. }\end{array}$ & $\%$ & $\begin{array}{c}\text { No. of } \\
\text { Patients/Total } \\
\text { No. }\end{array}$ & $\%$ & $\begin{array}{c}\text { No. of } \\
\text { Patients/Total } \\
\text { No. }\end{array}$ & $\%$ & $\begin{array}{c}\text { No. of } \\
\text { Patients/Total } \\
\text { No. }\end{array}$ & $\%$ & $\begin{array}{c}\text { No. of } \\
\text { Patients/Total } \\
\text { No. }\end{array}$ & $\%$ & & \\
\hline $\mathrm{B} 2 \mathrm{M} \geq 3.5 \mu \mathrm{g} / \mathrm{mL}$ & $106 / 238$ & 45 & $507 / 1,139$ & 45 & $1,354 / 2,622$ & 52 & $1,723 / 2,882$ & 60 & $922 / 1,366$ & 67 & $142 / 191$ & 74 & 0.16 & 0.14 to 0.19 \\
\hline Albumin $<3.5 \mathrm{~g} / \mathrm{dL}$ & $80 / 251$ & 32 & $378 / 1,145$ & 33 & $1,044 / 2,758$ & 38 & $1,325 / 3,224$ & 41 & $757 / 1,651$ & 46 & $150 / 279$ & 54 & -0.11 & -0.13 to -0.09 \\
\hline $\mathrm{HgB}<10 \mathrm{~g} / \mathrm{dL}$ & $114 / 294$ & 39 & $482 / 1,320$ & 37 & $1,186 / 3,103$ & 38 & $1,409 / 3,459$ & 41 & $724 / 1,689$ & 43 & $146 / 288$ & 51 & -0.08 & -0.10 to -0.06 \\
\hline Creatinine $\geq 2 \mathrm{mg} / \mathrm{dL}$ & $51 / 287$ & 18 & $189 / 1,307$ & 14 & $502 / 3,107$ & 16 & $582 / 3,480$ & 17 & $341 / 1,702$ & 20 & $59 / 284$ & 21 & 0.07 & 0.05 to 0.09 \\
\hline $\begin{array}{c}\text { Platelets }<130 \times \\
10^{3} / \mu \mathrm{L}\end{array}$ & $36 / 247$ & 15 & $116 / 1,173$ & 10 & $312 / 2,832$ & 11 & $432 / 3,359$ & 13 & 199/1,690 & 12 & $41 / 287$ & 14 & -0.04 & -0.06 to -0.02 \\
\hline Calcium $\geq 10 \mathrm{mg} / \mathrm{dL}$ & $88 / 256$ & 34 & $393 / 1,189$ & 33 & $999 / 2,867$ & 35 & $1,076 / 3,201$ & 34 & $501 / 1,545$ & 32 & $76 / 257$ & 30 & -0.02 & -0.04 to -0.00 \\
\hline $\mathrm{CRP} \geq 0.8 \mathrm{mg} / \mathrm{dL}$ & $27 / 117$ & 23 & $142 / 578$ & 25 & $412 / 1,431$ & 29 & $444 / 1,477$ & 30 & 205/704 & 29 & $38 / 128$ & 30 & 0.06 & 0.03 to 0.09 \\
\hline BMPC $\geq 33 \%$ & $165 / 279$ & 59 & $727 / 1,265$ & 57 & $1,741 / 2,984$ & 58 & $1,990 / 3,336$ & 60 & $986 / 1,652$ & 60 & $160 / 278$ & 58 & 0.00 & -0.02 to 0.02 \\
\hline LDH $>$ normal & $30 / 95$ & 32 & $128 / 505$ & 25 & $337 / 1,307$ & 26 & $369 / 1,343$ & 27 & $156 / 603$ & 26 & $26 / 112$ & 23 & -0.03 & -0.06 to 0.00 \\
\hline ISS stage & & & & & & & & & & & & & 0.13 & 0.11 to 0.16 \\
\hline 1 & $89 / 219$ & 41 & $403 / 1,048$ & 38 & $785 / 2,456$ & 32 & 709/2,783 & 25 & $274 / 1,350$ & 20 & $22 / 187$ & 12 & & \\
\hline$\|$ & $63 / 219$ & 29 & $375 / 1,048$ & 36 & $929 / 2,456$ & 38 & $1,115 / 2,783$ & 40 & $549 / 1,350$ & 41 & $82 / 187$ & 44 & & \\
\hline III & $67 / 219$ & 31 & $270 / 1,048$ & 26 & $742 / 2,456$ & 30 & $959 / 2,783$ & 34 & $527 / 1,350$ & 39 & $83 / 187$ & 44 & & \\
\hline
\end{tabular}

Abbreviations: B2M, $\beta_{2}$-microglobulin; $\mathrm{HgB}$, hemoglobin; CRP, C-reactive protein; BMPC, bone marrow plasma cells; LDH, lactate dehydrogenase.

In the entire group of patients, the average years of life lost per patient was 16.8 years. The average of years of life lost was highest in patients younger than age 40 years (36.1 years) and decreased steadily (Fig 1B) in patients age 40 to 49,50 to 59,60 to 69,70 to 79 , and $\geq 80$ (26.9, 19.9, 13.7, 8.1, and 4.6 years, respectively; Table 4). Similar figures with some variations were observed for men and women (Table 4) and for patients treated with standard or high-dose chemotherapy (Table 5). Average years of life lost in patients treated with conventional therapy seemed to be approximately 2 years greater in the age cohorts between 40 and 59 years but 2 years less in patients $\geq$ age 70 compared with patients treated with high-dose therapy (Table 5).

For all 10,549 patients included in this analysis, the total number of potential years of life lost amounted to 177,306 years (Table 4). Using a standard value of a year of life for men and women of all ages (ie, \$150,000), the value of life-years lost in a myeloma patient diagnosed at age 50 amounts to $\$ 4,035,000$, and the value of life-years lost in the entire study population equals $\$ 26,595,900,000$.

\section{DISCUSSION}

This study documents the significant age dependency of survival in MM. Mean observed survival was 3.7 years in the entire cohort and 6.3 years in patients age less than 50 years. Mean observed survival decreased steadily and significantly with each age decade to 2.5 years in patients age $\geq 80$ years. This correlation is remarkable and probably not a result of an increasingly more aggressive phenotype of the myeloma clone because typical risk factors for a more rapid tumor progression, such as lactate dehydrogenase or bone marrow myeloma cell infiltration, did not vary between patients of different age cohorts. The majority of previous studies were also unable to find significant imbalances of cytogenetic risk factors between older and younger patients, ${ }^{14,15}$ and in a small subgroup of 385 patients enrolled onto this study, no correlations between the proportion cytogenetic risk factors and age were observed (data not shown). However, we found a remarkable correlation between older age and more advanced ISS stage; $41 \%$ of patients younger than 40 years of age presented with ISS stage I, but only $12 \%$ of patients age $\geq 80$ years presented with ISS stage I. ISS stage is defined by $\beta_{2}$-microglobulin and albumin, both of which correlated with age, with $\beta_{2}$-microglobulin being more closely associated. $\beta_{2}$-Microglobulin is an important constituent of the HLA class I surface molecule, ${ }^{16}$ which presents intracellularly processed antigens to $\mathrm{CD} 8^{+} \mathrm{T}$ lymphocytes. $\beta_{2}$-Microglobulin serum levels have been found to correlate with age, ${ }^{17}$ renal function, ${ }^{18}$ and survival in a series of diseases such as chronic lymphocytic leukemia, ${ }^{19}$ Hodgkin's disease, ${ }^{20}$ non-Hodgkin's lymphoma, ${ }^{21}$ and chronic myelogenous leukemia. ${ }^{22}$ Our results show that $\beta_{2}$-microglobulin levels do not correlate with bone marrow myeloma cell infiltration and thus do not directly reflect the tumor mass. Because higher $\beta_{2}$-microglobulin levels predict poorer outcome in patients with similar stage and age, increased levels may mirror the host's attempt to overcome an insufficient T-cell response against the tumor. This phenomenon seems to accelerate with increasing age and is likely to contribute to poorer outcome in elderly patients. It may also explain, in part, why overall survival has not been improved in the elderly population of myeloma patients after the introduction of immunostimulatory drugs like thalidomide and lenalidomide. ${ }^{23}$

Our study revealed an average of 16.8 years of life lost per patient in the entire cohort of 10,549 myeloma patients enrolled onto this study. This is significantly higher than the 12.5 years reported for all cancers combined ${ }^{24}$ and greater than previously reported for MM. For 2004, the US National Center of Health Statistics reported an average of 14.0 years of life lost for patients with myeloma, with a median age at diagnosis of 70 years. ${ }^{25}$ In 2007, the British Columbia Cancer Registry reported an average of 12.7 years of life lost as a result of myeloma, whereas for the East Anglia region in the United Kingdom, an average of 10.3 years of life lost was calculated for patients with MM using data obtained between 1990 and $1994 .^{24}$ The main 

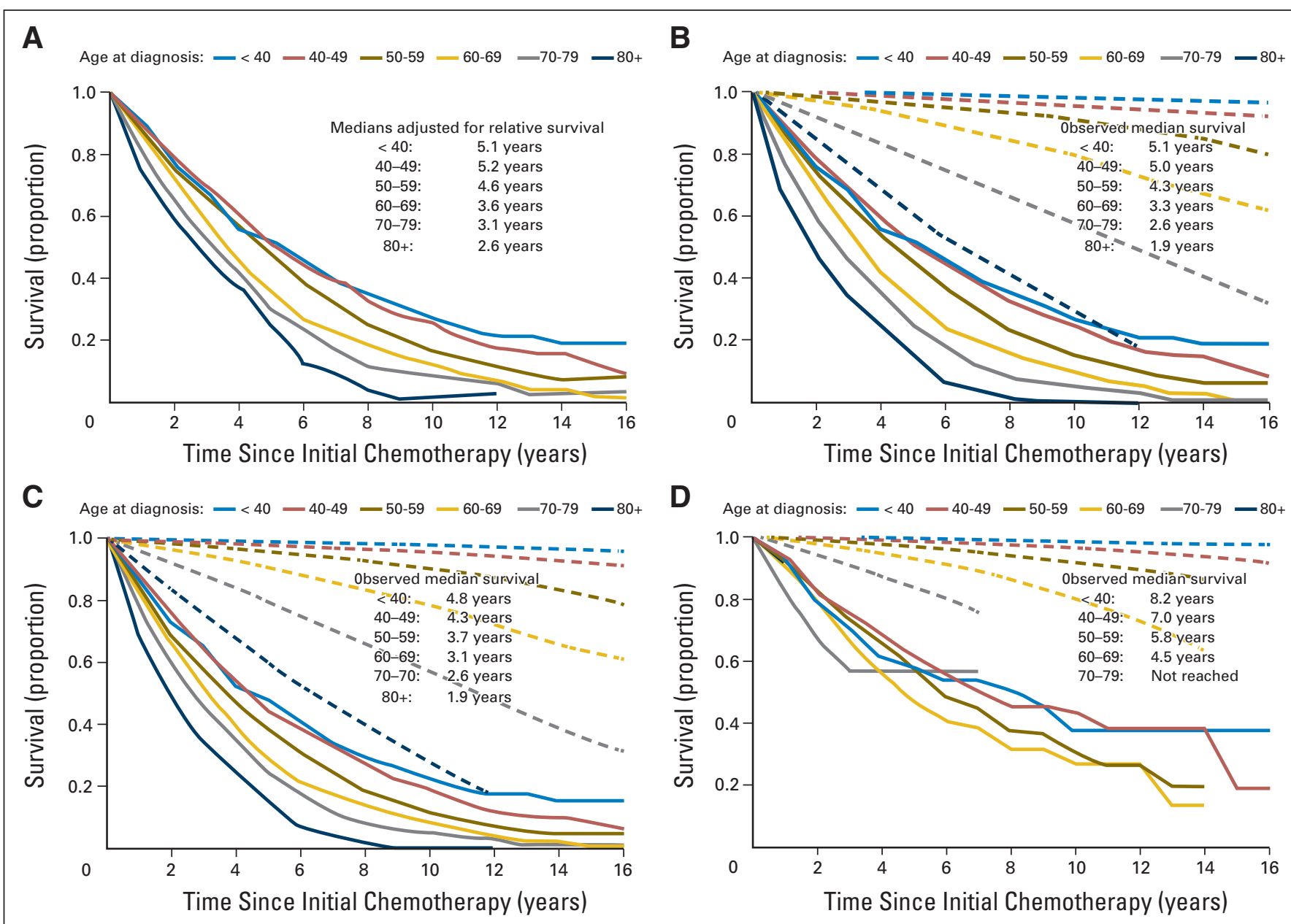

Fig 1. (A) Relative overall survival and (B) observed and expected overall survival in patients according to age at diagnosis. (C) Observed and expected survival in patients treated with conventional chemotherapy according to age at diagnosis. (D) Observed and expected survival in patients treated with high-dose chemotherapy according to age at diagnosis. Solid lines represent observed survival, and dashed lines represent expected survival.

reason for this discrepancy can be ascribed to the lower age of our patients (median age, 60 years), $70 \%$ of whom had been enrolled onto clinical studies and $30 \%$ of whom were referred for treatment to specialized myeloma centers ${ }^{5}$; in the routine clinical setting, patients are seen at a median age of diagnosis of 70 to 72 years.

This analysis shows the strong dependency of the potential loss of years of life on the age at diagnosis of the disease. The average number of years of life lost decreased more than nine-fold from 36.1 years in patients diagnosed before age 40 years to 4.6 years in patients $\geq$ age 80 years. Another interesting observation is the lesser loss of years of life in the patients age 40 to 49 and 50 to 59 years treated with high-dose chemotherapy and autologous stem-cell transplantation (25.6 and 18.2 years, respectively) compared with conventional therapy (27.4 and 21.0 years, respectively); however, this comparison is limited by the retrospective and nonrandomized nature. Still, this finding corresponds with the notion that the greatest benefit of highdose therapy and autologous transplantation is derived in patients between 40 and 59 years of age, ${ }^{26}$ whereas in patients older or younger than this age range, the impact on overall survival of this therapy seems less pronounced.

The total number of estimated years of life lost in our patient cohort is 177,306 years, a figure that is slightly higher than the esti- mated 151,100 years of life lost for the 10,670 US patients with myeloma who died in the year 2004. ${ }^{3}$ This higher number is probably a reflection of the younger age of the patients in this analysis.

Some limitations to the present study warrant mention. First, patients analyzed in this study were enrolled over a long period (1982 to 2002). We previously showed that in patients started on conventional therapy, survival increased significantly in patients enrolled between 1998 and 2002 compared with patients entered earlier. ${ }^{5}$ This did not apply to patients treated with high-dose chemotherapy followed by autologous transplantation. Although the improvement in survival in patients enrolled during the last period seems to be partly a result of the introduction of novel drugs, other factors, such as a higher proportion of patients receiving a transplantation at relapse, better supportive care, and a shift in prognostic factors with more patients presenting with more favorable risk factors than previously, may have contributed to the slightly but significantly longer survival. ${ }^{5}$ The longer survival expected with the newly available drugs and the other changes mentioned should markedly reduce the years of life lost of younger patients in the future. Second, forecasting life expectancy by extrapolating from the past does not account for possible new, lifeprolonging treatments and may thus underestimate the future gains in survival, limiting the precision of present estimates. Third, there was 
Table 3. Relative Excess Risk of Death in Various Patient Subgroups

\begin{tabular}{|c|c|c|c|}
\hline $\begin{array}{l}\text { Subgroup and Age } \\
\text { Category }\end{array}$ & RER & $95 \% \mathrm{Cl}$ & $P$ \\
\hline \multicolumn{4}{|l|}{ Age, years } \\
\hline$<40 \vee 40-49$ & 1.03 & 0.88 to 1.22 & .692 \\
\hline $40-49 \vee 50-59$ & 1.20 & 1.10 to 1.31 & $<.001$ \\
\hline $50-59$ v 60-69 & 1.29 & 1.21 to 1.37 & $<.001$ \\
\hline $60-69$ × 70-79 & 1.19 & 1.10 to 1.28 & $<.001$ \\
\hline 70-79 v80+ & 1.28 & 1.07 to 1.52 & .009 \\
\hline \multicolumn{4}{|l|}{ Males } \\
\hline$<40 \vee 40-49$ & 1.02 & 0.84 to 1.26 & .818 \\
\hline $40-49$ v 50-59 & 1.25 & 1.11 to 1.40 & $<.001$ \\
\hline $50-59$ v 60-69 & 1.30 & 1.20 to 1.42 & $<.001$ \\
\hline $60-69 \vee 70-79$ & 1.21 & 1.09 to 1.35 & $<.001$ \\
\hline 70-79 v 80+ & 1.31 & 0.99 to 1.72 & .068 \\
\hline \multicolumn{4}{|l|}{ Females } \\
\hline$<40 \vee 40-49$ & 1.05 & 0.79 to 1.38 & .757 \\
\hline $40-49$ v 50-59 & 1.14 & 0.99 to 1.31 & .051 \\
\hline $50-59 \vee 60-69$ & 1.27 & 1.15 to 1.41 & $<.001$ \\
\hline $60-69$ × 70-79 & 1.18 & 1.05 to 1.32 & .005 \\
\hline 70-79 v80+ & 1.28 & 1.02 to 1.61 & .046 \\
\hline \multicolumn{4}{|c|}{ Conventional chemotherapy } \\
\hline$<40 \vee 40-49$ & 1.09 & 0.90 to 1.32 & .359 \\
\hline $40-49$ v 50-59 & 1.22 & 1.11 to 1.35 & $<.001$ \\
\hline $50-59$ v 60-69 & 1.16 & 1.08 to 1.25 & $<.001$ \\
\hline $60-69$ × 70-79 & 1.11 & 1.02 to 1.20 & .012 \\
\hline 70-79 v 80+ & 1.27 & 1.07 to 1.52 & .010 \\
\hline \multicolumn{4}{|l|}{ High-dose therapy } \\
\hline$<40 \vee 40-49$ & 0.93 & 0.37 to 1.30 & .685 \\
\hline $40-49$ v 50-59 & 1.10 & 0.92 to 1.31 & .282 \\
\hline $50-59 \vee 60-69$ & 1.26 & 1.07 to 1.49 & .006 \\
\hline $60-69 \vee 70-79$ & 1.13 & 0.55 to 2.33 & .746 \\
\hline 70-79 v 80+ & - & - & - \\
\hline
\end{tabular}

Abbreviation: RER, relative excess risk.

significant heterogeneity in the age distribution and inclusion of patients in clinical trials. Patients from Asia were older than those from North America and Europe. All of the Asian patients had been studied within clinical trials, whereas $80.2 \%$ of the European and $72.3 \%$ of the
North American patients participated in clinical studies. Fourth, the patients included in this analysis, particularly the elderly cohort, were likely in better condition than the general population of myeloma patients that are not entered onto clinical studies because of multimorbidity and/or severe myeloma-related complications such as marked renal impairment or severely suppressed hematopoiesis. Hence, the influence of age might even be greater in a populationbased study. Finally, several approaches can be used to estimate the economic burden of mortality. We applied the willingness-to-pay approach that incorporates both lost productivity as a result of death and the intrinsic value of life by estimating the amount an average individual would be willing to pay for an additional year of life. ${ }^{27} \mathrm{We}$ used the commonly used value of $\$ 150,000$ for a year of life, which is based on prior research ${ }^{13}$ on the willingness to pay for an additional year of life. Other methods, such as the human capital approach, ${ }^{28}$ put more emphasis on sex- and age-specific average earnings and combine these values with expected productivity trends and years of life lost to earnings.

Using a standard value of life ${ }^{13,29}$ for men and women of all ages (ie, $\$ 150,000$ ) the value of life lost for our myeloma patients amounts to $\$ 26,595,900,000$. Although this figure shows the substantial economic loss of myeloma for the society, the personal loss experienced by the people close to the patient is usually enormous and cannot be measured in financial terms.

In conclusion, age is associated with higher ISS stage and is an important risk factor for early mortality in MM. In addition, survival declines continuously by each decade from age 50 to age $\geq 80$ years, even after adjustment for expected mortality. Because of the still relatively short survival of patients with myeloma, the loss in years of life in patients with manifestation before age 40 is greatest and amounts to 36 years, whereas in patients diagnosed at age $\geq 80$, the average loss of years of life is approximately 4 to 5 years. Widespread use of the novel drugs thalidomide, bortezomib, and lenalidomide is likely to reduce the loss of precious life time but will not transform myeloma into a chronic disease with a life expectancy similar to that of the healthy population. Better understanding of the underlying process of malignant transformation and tumor propagation ultimately should

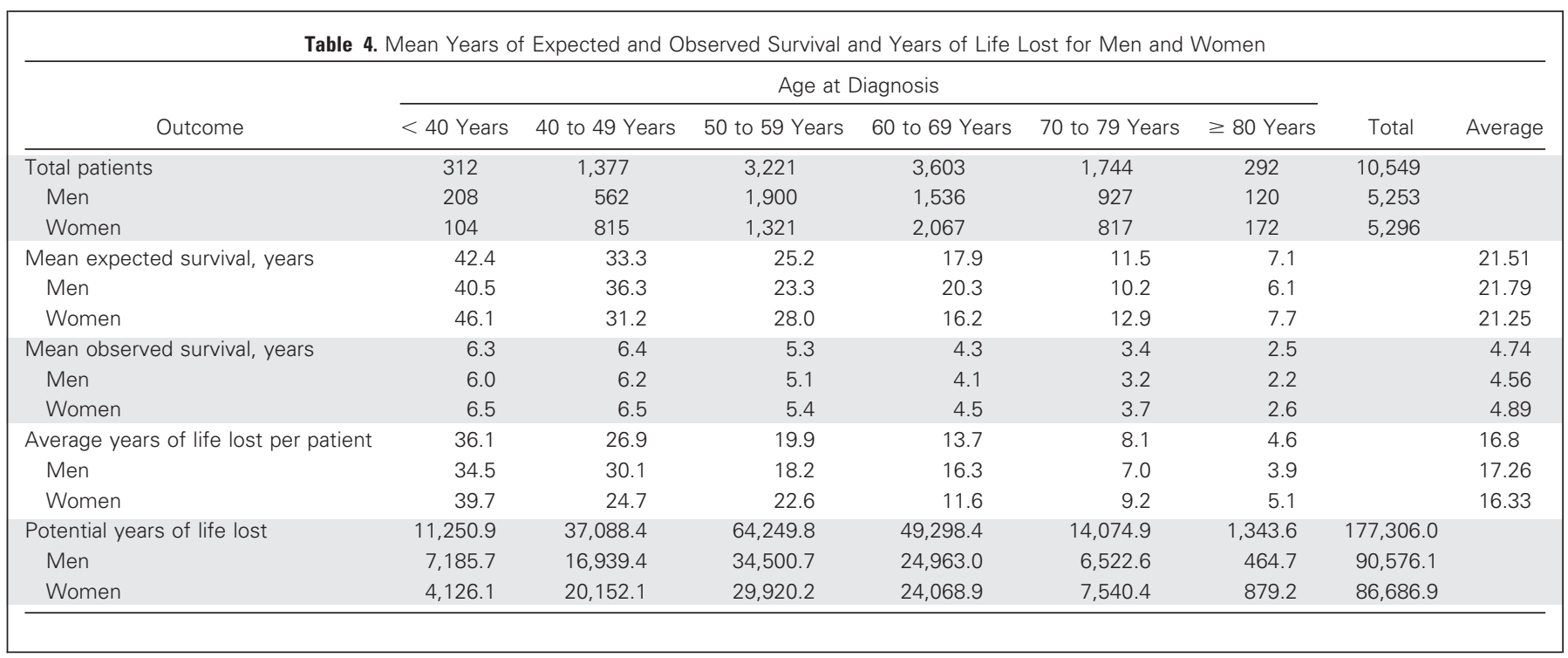




\begin{tabular}{|c|c|c|c|c|c|c|}
\hline \multirow[b]{2}{*}{ Treatment } & \multicolumn{6}{|c|}{ Age at Diagnosis } \\
\hline & $<40$ Years & 40 to 49 Years & 50 to 59 Years & 60 to 69 Years & 70 to 79 Years & $\geq 80$ Years \\
\hline \multicolumn{7}{|l|}{ Conventional chemotherapy } \\
\hline No. of patients & 123 & 805 & 1,259 & 2,809 & 1,709 & 291 \\
\hline Mean expected survival, years & 42.7 & 33.1 & 25.7 & 17.6 & 11.5 & 7.1 \\
\hline Mean observed survival, years & 5.9 & 5.7 & 4.7 & 4.0 & 3.4 & 2.5 \\
\hline Average years of life lost per patient & 36.8 & 27.4 & 21.0 & 13.6 & 8.1 & 4.6 \\
\hline \multicolumn{7}{|l|}{ High-dose chemotherapy } \\
\hline No. of patients & 189 & 572 & 1,962 & 794 & 35 & 1 \\
\hline Mean expected survival, years & 42.2 & 33.6 & 25 & 19.3 & 12.7 & 6.1 \\
\hline Mean observed survival, years & 6.3 & 8.0 & 6.7 & 6.2 & 2.1 & - \\
\hline Average years of life lost per patient & 35.9 & 25.6 & 18.2 & 13.1 & 10.6 & - \\
\hline
\end{tabular}

enable the development of more efficient therapy and better outcome of patients afflicted with this still difficult to treat disease.

\section{AUTHORS' DISCLOSURES OF POTENTIAL CONFLICTS} OF INTEREST

Although all authors completed the disclosure declaration, the following author(s) indicated a financial or other interest that is relevant to the subject matter under consideration in this article. Certain relationships marked with a " $U$ " are those for which no compensation was received; those relationships marked with a " $C$ " were compensated. For a detailed description of the disclosure categories, or for more information about ASCO's conflict of interest policy, please refer to the Author Disclosure Declaration and the Disclosures of Potential Conflicts of Interest section in Information for Contributors.

Employment or Leadership Position: None Consultant or Advisory Role: Heinz Ludwig, Ortho Biotech (C), Celgene (C), Amgen (U); Pieter Sonneveld, Janssen-Cilag (C); Mario Boccadoro, Celgene (C), Janssen-Cilag (C); Antonio Palumbo, Celgene (C), Janssen-Cilag (C); Jean-Luc Harousseau, Celgene (C), Janssen-Cilag (C); Michel Attal, Janssen-Cilag (C), Celgene (C); Bart Barlogie, Celgene (C), Millennium Pharmaceuticals (C), Novartis (C); Brian Durie, Celgene (C), Millenium Pharmaceuticals (C) Stock Ownership: None Honoraria: Heinz Ludwig, Amgen, Ortho Biotech, Celgene, Mundipharma; Joan Bladé, Janssen-Cilag, Celgene, Novartis; Pieter Sonneveld, Millennium Pharmaceuticals, Celgene, Janssen-Cilag Ortho Biotech; Antonio Palumbo, Celgene, Janssen-Cilag; Jean-Luc Harousseau, Genzyme, Amgen Research Funding: Heinz Ludwig, Schering-Plough, Ortho
Biotech, Celgene, Mundipharma; Joan Bladé, Celgene, Janssen-Cilag; Mario Boccadoro, Celgene, Janssen-Cilag; Bart Barlogie, National Cancer Institute Expert Testimony: None Other Remuneration: None

\section{AUTHOR CONTRIBUTIONS}

Conception and design: Heinz Ludwig, Vanessa Bolejack, John Crowley, S. Vincent Rajkumar, Pieter Sonneveld, Bart Barlogie, Brian Durie Provision of study materials or patients: Heinz Ludwig, Joan Bladé, Jesus San Miguel, Kazuyuki Shimizu, Ingemar Turesson, Jan Westin, Pieter Sonneveld, Michele Cavo, Mario Boccadoro, Antonio Palumbo, Patrizia Tosi, Jean-Luc Harousseau, Michel Attal, Bart Barlogie,

A. Keith Stewart

Collection and assembly of data: Vanessa Bolejack, John Crowley, Kazuyuki Shimizu, Ingemar Turesson, Jan Westin, Patrizia Tosi, Bart Barlogie, Brian Durie

Data analysis and interpretation: Heinz Ludwig, Vanessa Bolejack, John Crowley, Robert A. Kyle, Jan Westin, Pieter Sonneveld

Manuscript writing: Heinz Ludwig, Vanessa Bolejack, John Crowley, Joan Bladé, Jesus San Miguel, Robert A. Kyle, S. Vincent Rajkumar, Pieter Sonneveld, Antonio Palumbo, Bart Barlogie, Brian Durie Final approval of manuscript: Heinz Ludwig, Vanessa Bolejack, John Crowley, Joan Bladé, Jesus San Miguel, Robert A. Kyle, S. Vincent Rajkumar, Kazuyuki Shimizu, Ingemar Turesson, Jan Westin, Pieter Sonneveld, Michele Cavo, Mario Boccadoro, Antonio Palumbo, Patrizia Tosi, Jean-Luc Harousseau, Michel Attal, Bart Barlogie, A. Keith Stewart, Brian Durie

\section{REFERENCES}

1. Jemal A, Siegel $R$, Ward $E$, et al: Cancer statistics, 2008. CA Cancer J Clin 58:71-96, 2008

2. Boyle P, Ferlay J: Cancer incidence and mortality in Europe, 2004. Ann Oncol 16:481-488, 2005

3. National Cancer Institute: SEER cancer statistics review 1975-2005: US mortality files, National Center for Health Statistics, Center for Disease Control and Prevention and 2004 life tables. http://www.seer .cancer.gov/csr/1975_2004/results_merged/sect_01_ overview.pdf

4. Ludwig H, Fritz E, Friedl HP: Epidemiologic and age-dependent data on multiple myeloma in Austria. J Natl Cancer Inst 68:729-733, 1982

5. Ludwig $H$, Durie B, Bolejack $V$, et al: Myeloma in patients under age 50 presents with more favorable features and shows better survival: An analysis of 10,549 patients from the International Myeloma Working Group. Blood 111 : 4039-4047, 2008

6. Kristinsson SY, Landgren O, Dickman PW, et al: Patterns of survival in multiple myeloma: A population-based study of patients diagnosed in Sweden from 1973 to 2003. J Clin Oncol 25:19931999, 2007

7. Riccardi A, Mora O, Brugnatelli $S$, et al: Relevance of age on survival of 341 patients with multiple myeloma treated with conventional chemotherapy: Updated results of the MM87 prospective randomized protocol-Cooperative Group of Study and Treatment of Multiple Myeloma. $\mathrm{Br} \mathrm{J}$ Cancer 77:485-491, 1998

8. Spearman C: The proof and measurement of association between two things. Am J Psychol 100:441-471, 1904
9. Dickman $P$, Sloggett $A$, Hills $M$, et al: Regression models for relative survival. Stat Med 23:51-64, 2004

10. Kaplan EL, Meier P: Nonparametric estimation from incomplete observations. J Am Stat Assoc 53:457-481, 1958

11. Mantel N: Evaluation of survival data and two new rank order statistics arising in its consideration. Cancer Chemother Rep 50:163-170, 1966

12. University of California, Berkeley and Max Planck Institute for Demographic Research: Human mortality database. http://www.mortality.org/

13. Cutler DM, Gruber J, Hartman RS, et al: The economic impacts of the tobacco settlement, 2008; NBER Working Paper No. W7760. http://ssrn.com/ abstract $=235716$

14. Nilsson $T$, Lenhoff $S$, Turesson I, et al: Cytogenetic features of multiple myeloma: Impact of gender, age, disease phase, culture time, and cytokine stimulation. Eur J Haematol 68:345-353, 2002 
15. Sagaster $V$, Kaufmann $H$, Odelga $V$, et al: Chromosomal abnormalities of young multiple myeloma patients ( $<45 \mathrm{yr}$ ) are not different from those of other age groups and are independent of stage according to the International Staging System. Eur J Haematol 78:227-234, 2007

16. Grey HM, Kubo RT, Colon SM, et al: The small subunit of HL-A antigens is beta 2-microglobulin. J Exp Med 138:1608-1612, 1973

17. Teasdale $C$, Mander AM, Fifield $R$, et al: Serum beta2-microglobulin in controls and cancer patients. Clin Chim Acta 78:135-143, 1977

18. Wibell L, Evrin PE, Berggård I: Serum 2microglobulin in renal disease. Nephron 10:320-331, 1973

19. Keating $M J$, Lerner $S$, Kantarjian $H$, et al: The serum B2-microclobulin level is more powerful than stage in predicting response and survival in chronic lymphocytic leukemia. Blood 86:606, 1995 (abstr)
20. Dimopoulos MA, Cabanillas F, Lee JJ, et al: Prognostic role of serum beta 2-microglobulin in Hodgkin's disease. J Clin Oncol 11:1108-1111, 1993

21. Litam P, Swan F, Cabanillas F, et al: Prognostic value of serum beta-2 microglobulin in low-grade lymphoma. Ann Intern Med 114:855860,1991

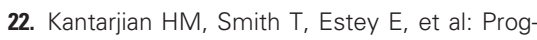
nostic significance of elevated serum beta 2microglobulin levels in adult acute lymphocytic leukemia. Am J Med 93:599-604, 1992

23. Kumar SK, Rajkumar SV, Dispenzieri A, et al: Improved survival in multiple myeloma and the impact of novel therapies. Blood 111:2516-2520, 2008

24. Burnet NG, Jefferies SJ, Benson RJ, et al: Years of life lost (YLL) from cancer is an important measure of population burden and should be considered when allocating research funds. $\mathrm{Br} \mathrm{J}$ Cancer 92:241-245, 2005
25. US National Center of Health Statistics: Cancer trends progress report-2007 update.http:// progressreport.cancer.gov/doc_detail.asp?pid=1\& $\mathrm{did}=2007 \&$ chid $=76 \&$ coid $=730 \&$ mid $=$ \#estimate

26. Lenhoff S, Hjorth M, Westin J, et al: Impact of age on survival after intensive therapy for multiple myeloma: A population-based study by the Nordic Myeloma Study Group. Br J Haematol 133:389-396, 2006

27. Brown ML, Yabroff $\mathrm{KR}$ : Economic impact of cancer in the United States, in Schottenfeld D, Faumeni J (eds): Cancer Epidemiology and Prevention. New York, NY, Oxford University Press, 2006, pp 202-214

28. Mincer J: The distribution of labor incomes: $A$ survey with special reference to the human capital approach. J Econ Lit 8:1-26, 1970

29. Yabroff RK, Bradley CJ, Mariotto AB, et al: Estimates and projections of value of life lost from cancer deaths in the United States. J Natl Cancer Inst 100:1755-1762, 2008

\section{Journal of Oncology Practice Now Available on PubMed Central}

Beginning with the January 2010 issue, full text for all JOP articles will be available on the NIH PubMed Central archive 4 months after publication. Once available, content is then delivered to PubMed, a metadata repository overseen by the National Library of Medicine and used by many scientific, technical, and medical researchers, making JOP material discoverable in PubMed for the first time.

Find yourself in PubMed. Submit your manuscript to JOP at jopsubmissions@ asco.org. 